\title{
A nonmagnetic stereotaxic head holder for macaque monkeys
}

\author{
PETER TEALE, MARTIN REITE, and JACK SIMON \\ University of Colorado Health Sciences Center, Denver, Colorado
}

\begin{abstract}
In this paper, we describe the design and construction of a nonmetallic, nonmagnetic stereotaxic device for use in holding the head of anesthetized macaque monkeys during magnetic resonance and computerized axial tomography imaging procedures. Head movement can be eliminated, permitting the investigator to obtain maximal resolution from the imaging system.
\end{abstract}

The increasing precision of methods for quantifying and localizing brain function(s) requires similar improvements in precision in the determination of brain anatomy. Examples of such requirements in our laboratories include three-dimensional localization of magnetoencephalographic (MEG) determined auditory sources in human and nonhuman primate (macaque monkey) brains by using MEG-evoked field recordings and then determining neuroanatomical structures associated with such sources using magnetic resonance (MR) and/or computerized axial tomography (CT) imaging.

Structural imaging of the monkey brain can be greatly facilitated if the animal's head can be held reliably in a known position for the duration of MR or CT imaging. This report describes a completely nonmagnetic, nonmetallic, stereotaxic device used for holding the heads of macaque monkeys during MR or CT imaging of the brain. The device can, in addition, be used to correlate MR or CT images with EEG- or MEG-determined brain current sources.

\section{METHOD}

\section{Design and Construction}

We describe the design and construction of a nonmagnetic stereotaxic head holder that will restrain a monkey's head and that can be placed inside a standard human knee coil during MR imaging. The basic design of the eye bars, ear bars, and mouthpiece is based on the David Kopf Model 1204 primate stereotaxic instrument.

This device incorporates registration structures in the eye bars and ear bars that assist in collocating MR/CT images with conventional stereotaxic coordinates. The animal is anesthetized during the MR/CT imaging.

This work was supported by USPHS Grants MH46335 and MH44212. The first and second authors are affiliated with the Department of Psychiatry at the University of Colorado Health Sciences Center. The third author is affiliated with the Department of Radiology at the same institution. Correspondence should be addressed to $P$. Teale, Department of Psychiatry, Box C268-68, University of Colorado Health Sciences Center, 4200 E. Ninth Ave., Denver, CO 80262.

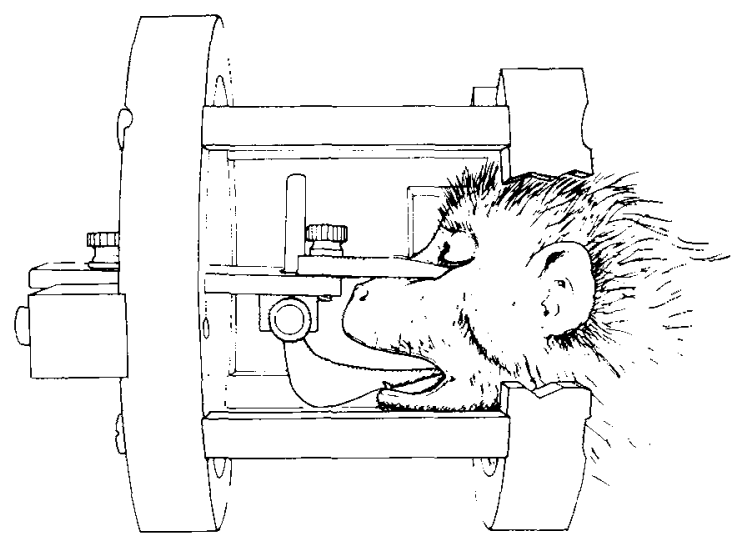

Figure 1. Lateral view of nonmetallic stereotaxic device with anesthetized macaque monkey in position.

The apparatus, illustrated in Figure 1 as a lateral view with the subject's head in place, is constructed as a frame consisting of two acrylic plastic rings $(17 \mathrm{~cm} \mathrm{o.d.,} 13.5 \mathrm{~cm}$ i.d., and $2.4 \mathrm{~cm}$ thickness) oriented vertically and coaxially, with four horizontal acrylic struts $(9 \mathrm{~cm}$ long $\times 2 \mathrm{~cm}$ wide $\times 1.25 \mathrm{~cm}$ thick) mounted between them, secured with nylon machine screws $(1 / 4-20 \times 1.5 \mathrm{in}$.). The crest of the rear ring $\left(80^{\circ}\right.$ of arc) was removed to allow for clearance in the event of skull cap preparations for implanted electrode arrays and so forth.

The struts are located at $\pm 40^{\circ}$ off horizontal, leaving $100^{\circ}$ of clear arc on top and bottom. All frame dimensions were chosen to accommodate the knee coil assembly used in the General Electric Signa 1.5 MR system. Figure 2 displays the device nested in the lower half section of the knee coil.

Across the front ring, a mounting bar $(17 \mathrm{~cm}$ long $\times$ $2.4 \mathrm{~cm}$ wide $\times 2.4 \mathrm{~cm}$ thick, acrylic) is centrally located with a milled slot $(5 \mathrm{~cm}$ wide $\times 3 \mathrm{~mm}$ deep $)$ on the top to accept a sliding carriage $(10 \mathrm{~cm}$ long $\times 5 \mathrm{~cm}$ wide $\times$ $6 \mathrm{~mm}$ thick, acrylic) to which the eye bars and the mouthpiece are attached with nylon thumb screws (10-32 $\times$ 1 in.). The carriage is slotted and can be adjusted (anterior- 


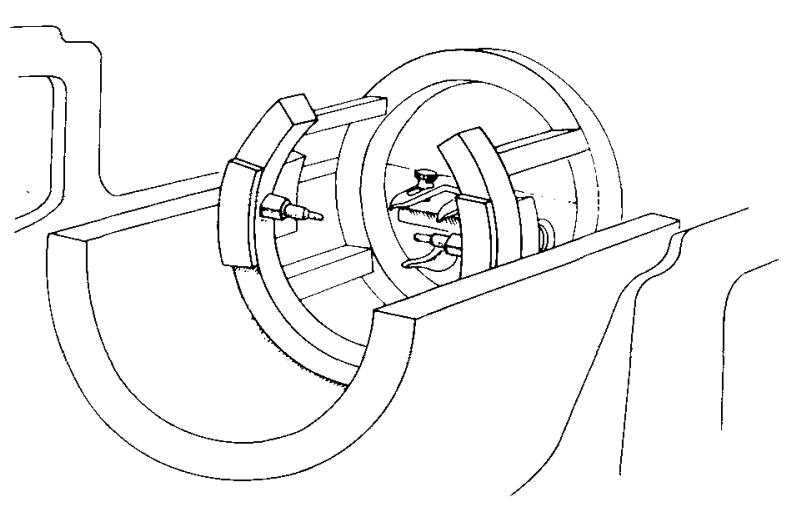

Figure 2. Rear view of stereotaxic device in place in lower half of human knee coil.

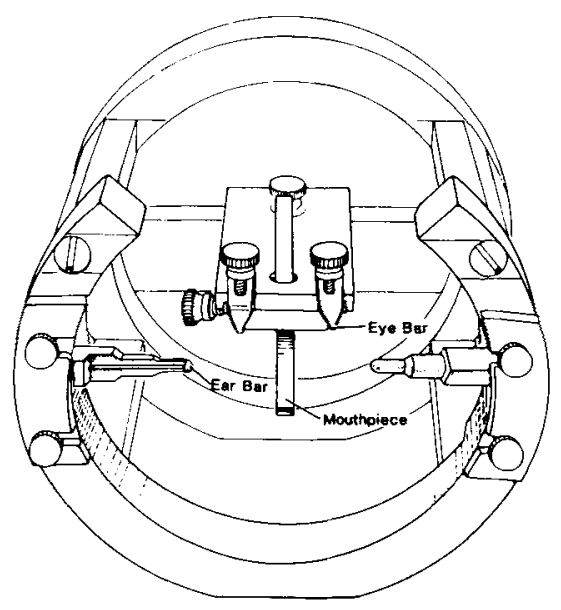

Figure 3. Posterior axial view of stereotaxic device. Aluminum handles (not shown) screw into the outside ends of each ear bar to facilitate manipulation and placernent of the bars.

posterior) over a range of $7 \mathrm{~cm}$, and is also secured with a nylon thumb screw. The eye bars $(5.5 \mathrm{~cm}$ long $\times 1 \mathrm{~cm}$ wide $\times 6 \mathrm{~mm}$ thick, polycarbonate) are also slotted, providing a $3-\mathrm{cm}$ adjustment range (anterior-posterior). A posterior axial view of the holder displays these features in Figure 3.

About $1.7 \mathrm{~cm}$ from the tip of each eye bar, a horizontal hole was bored and tapped for a 2-56 $\times 3 / 16$ in. nylon machine screw. The hole was $6 \mathrm{~mm}$ in depth and was slightly counterbored to accept a $1 / 8 \times 3 / 16$ Viton O-ring mounted on the machine screw, resulting in an interior cylindrical cavity approximately $2 \mathrm{~mm}$ in diameter and $3 \mathrm{~mm}$ in length, which is filled with a high-proton-density lipid solution (transparenteral nutrition, TPN) for MR imaging and is left empty for CT. The mouthpiece (6-mmthick polycarbonate) has a vertical adjustment range of $4 \mathrm{~cm}$. The ear bars are constructed of $1.25-\mathrm{cm}$-diameter Delrin rods, $5.5 \mathrm{~cm}$ long, and stepped down to a final diameter of $5 \mathrm{~mm}$ at the ear end for a length of $1.2 \mathrm{~cm}$.
These bars are mounted in slots along the horizontal centerline of the rear frame ring and are secured with acrylic retaining plates by nylon thumb screws $(8-32 \times 1 / 2$ in.). Each bar has a drilled hole, $2 \mathrm{~mm}$ in diameter and $5.3 \mathrm{~cm}$ in length, on axis with the open end out, counterbored $1.5 \mathrm{~cm}$ and capped with a $4-40 \times 1 / 4$ in. nylon machine screw and Viton O-ring. This is filled with TPN solution for MR imaging and left empty for CT scans. The ends are tapped $5 / 16 \times 18$ to accept removable aluminum handles of $1.25 \mathrm{~cm}$ diameter and $16 \mathrm{~cm}$ in length.

\section{Stereotaxic Coordinate System}

A standard stereotaxic coordinate system is established by using the ear bar and eye bar cavities, which show up, respectively, as bright white lines and dots in MR, and black lines and dots in CT. The horizontal reference plane is designated as that which contains both ear bars and the two points $2 \mathrm{~mm}$ below the eye bar indicators. The anteroposterior zero plane is orthogonal to this plane through the ear bar lines, and the lateral reference is orthogonal to both of these planes and is oriented along the axial center. Coordinates derived from this system are directly compatible with those used in commercial stereotaxic instruments-for example, the David Kopf Instruments Model 1204 or 1404.

\section{Subject Placement}

Following anesthesia (e.g., ketamine $10 \mathrm{mg} / \mathrm{kg}$ or phenobarbital $15 \mathrm{mg} / \mathrm{kg}$ ) the animal is placed in the head holder by first inserting the right ear bar, locking it in place with the animal's head approximately in the middle of the stereotaxic device, and inserting the left ear bar, which is then locked in place. The aluminum handles are then removed. Similar precautions are necessary when inserting ear bars as when using a conventional stereotaxic device. For example, in pigtail macaques, the external auditory canal angles sharply downward from the pinna. Thus, care must be taken to ensure that the ear bar does not become lodged in the suprameatal triangle (Winters, Kado, \& Adey, 1969). If the head is freely rotatable around the ear bars, and appears symmetric from a frontal view, the eye bars are then positioned over the inferior orbital ridge and the mouth bar is placed under the upper incisors, with the tongue kept clear of the bars. The head is then carefully inspected to make sure that both ears are level and symmetric. A preliminary coronal image through the ear bars is obtained to make sure that the bars are in the external auditory canals and are bilaterally symmetric in placement before the complete image series is begun. If the preliminary image indicates that asymmetric ear bar placement (lower or higher on one side than on the other) is necessary, the animal's head can be removed and reinserted at this time.

\section{DISCUSSION}

Figure 4 illustrates a coronal MR slice from a macaque monkey. Note that the high-proton-density central channels within the ear bars are well visualized in this image, 


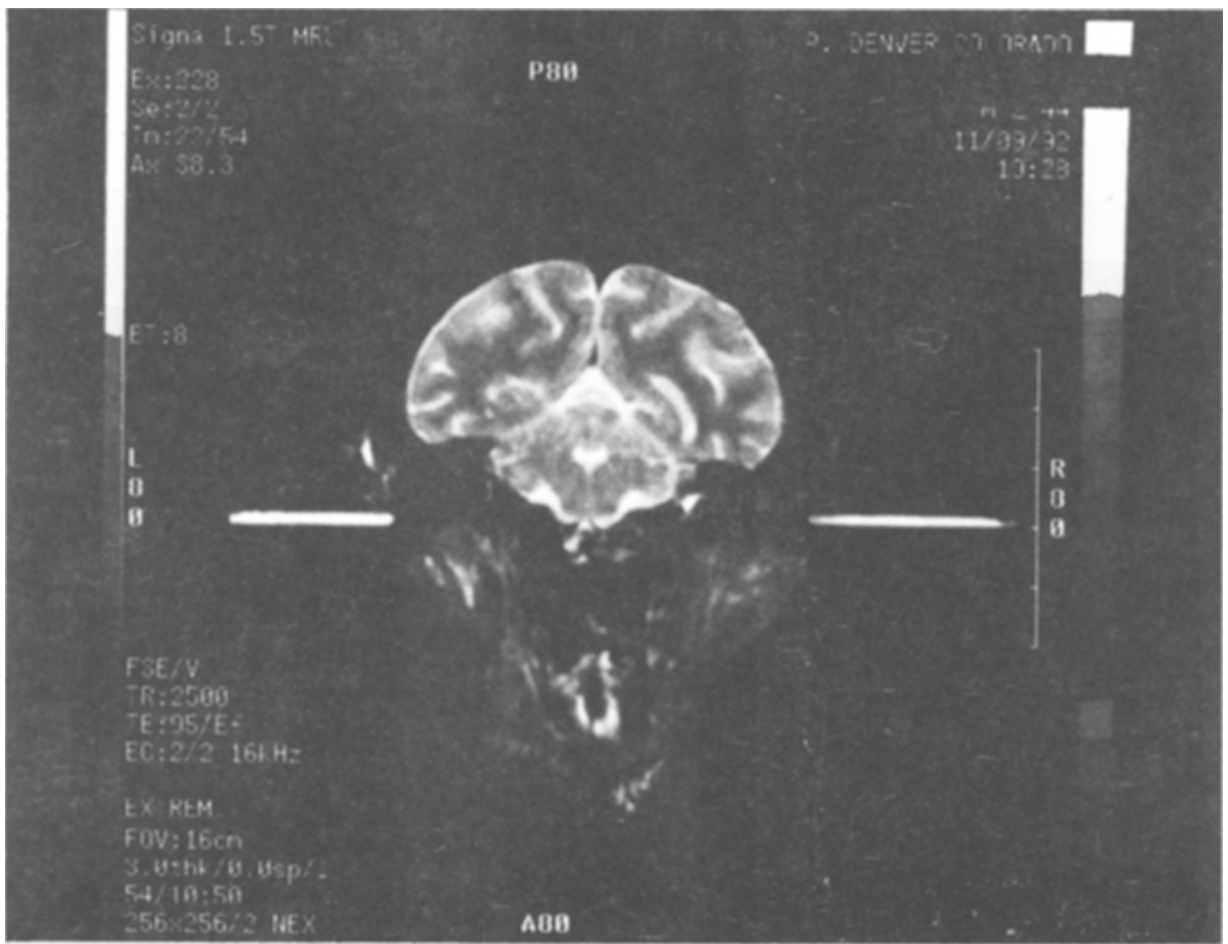

Figure 4. Coronal MR image obtained from 2-year-old macaque monkey. TR/TE $=2,500 / .05,256 \times 256$ pixels, field of view $16 \mathrm{~cm}$, and slice thickness of $3 \mathrm{~mm}$.

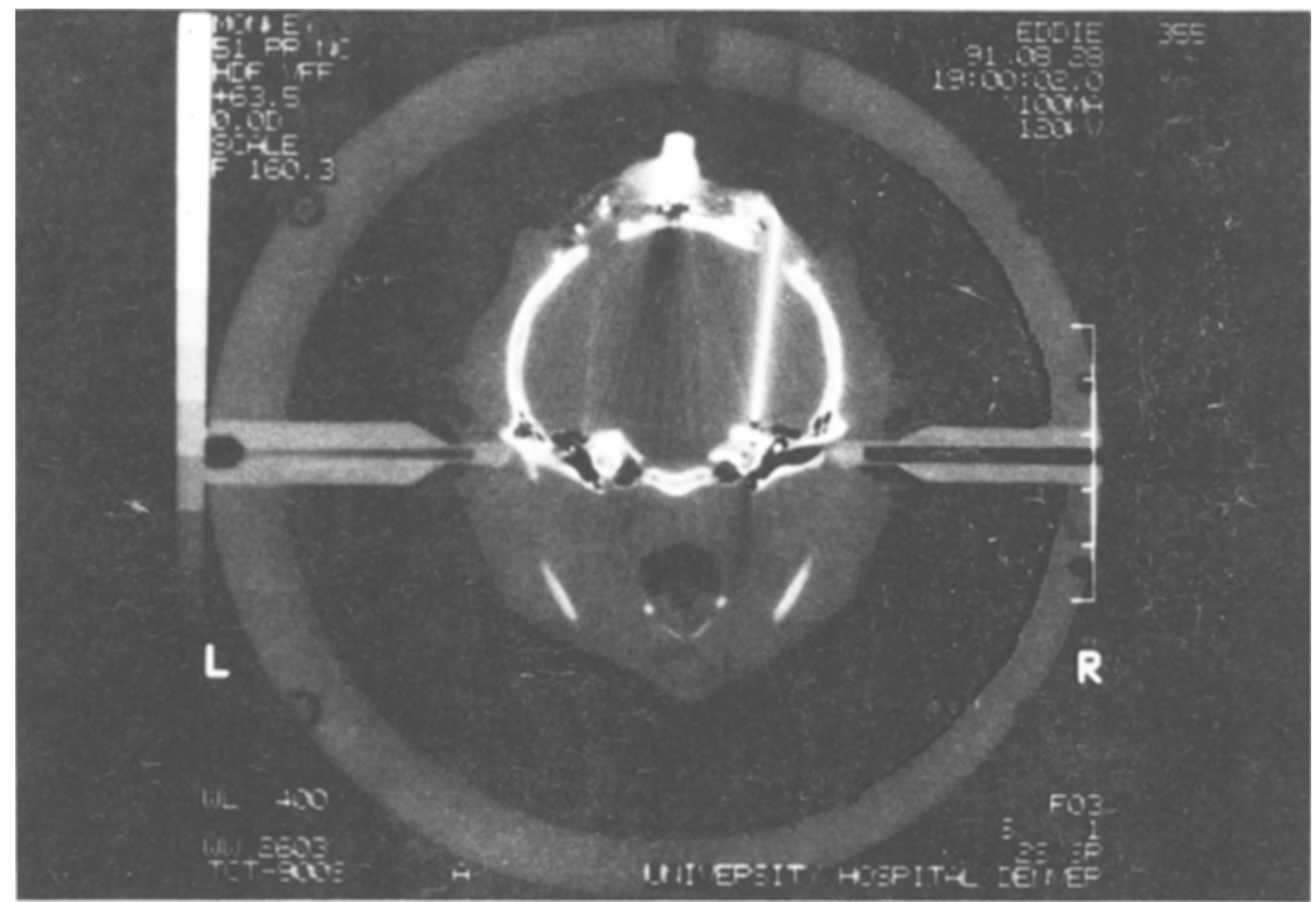

Figure 5. Coronal CT slice through brain of 2-year-old macaque monkey. CT acquired at $120 \mathrm{kV}$ and $100 \mathrm{ma}$ with Toshiba Model 9005 . Slice thickness is $1.0 \mathrm{~mm}$. 
providing a reference point for locating brain structures. Figure 5 is a coronal CT slice from the same subject. Note the black bars corresponding to the ear bar canals. The bright, near vertical, line is the image produced by a stainless steel electrode that was positioned with a standard metal stereotaxic device (David Kopf Model 1204), with coordinates derived from a set of MR images acquired by using the stereotaxic device described herein.

Utilization of this restraint system eliminates headmovement artifact that can interfere with image clarity and accuracy, and permits the investigator to obtain the maximum resolution obtainable from the imaging system. It also provides a common coordinate system for the various imaging modalities, simplifying registration issues and reducing the errors involved in transformation calculations.

If ketamine is the only anesthetic agent used, it is possible that some movement of the lower jaw will result in movement artifact in MR images. This can be prevented by taping the lower jaw closed or by using an anesthetic agent with greater powers of muscle relaxation, such as a barbiturate or possibly a short-acting benzodiazepine (Jacobs et al., 1993).

\section{REFERENCES}

Jacobs, B., Harris, G. C., Allada, V., Chugani, H. T., Pollack, D. B., RALEIGH, M. J. (1993). Midazolam as an effective intravenous adjuvant to prolonged ketamine sedation in young rhesus (Macaca mulatta) and vervet (Cercopithecus aethiops sabaeus) monkeys: A preliminary report. American Joumal of Primatology, 29, 291-298.

WINTERS, W., KADO, R., \& ADEY, W. (1969). A stereotaxic brain atlas for Macaca nemestrina. Berkeley \& Los Angeles: University of California Press.

(Manuscript received May 3, 1993; revision accepted for publication July 7,1993 .) 